\title{
Levantando o Véu do Regime de Direito Público
}

\author{
Lifting the Veil of the Public Legal Regime
}

\begin{abstract}
Resumo
O presente texto figura como introdução à Revista de Direito, Estado $e$ Telecomunicações do Grupo de Estudos em Direito das Telecomunicações da Universidade de Brasília, abordando sinteticamente os principais acontecimentos do setor no Brasil, bem como normas e julgados relativos ao ano de 2016, para registro das principais discussões político-jurídicas do setor de telecomunicações brasileiro referentes ao ano anterior ao da publicação.
\end{abstract}

Palavras-chave: política de telecomunicações, regulação de telecomunicações, arcabouço normativo de telecomunicações, Brasil.

\section{Abstract}

The article introduces this issue of the Law, State, and Telecommunications Review by way of presenting its contents. Statutes, the administrative regulation, and judicial decisions of 2016 pertaining to telecommunications are referred to in detail. It also addresses the main political and juridical discussions on the Brazilian telecommunications sector that took place the year before the publication of the journal's current volume.

Keywords: telecommunications policy, telecommunications regulation, telecommunications legal framework, Brazil.

\section{Apresentação}

O nono volume da Revista de Direito, Estado e Telecomunicações manteve o propósito inicial da publicação de consolidação da revista como um instrumento de pesquisa jurídica setorial com foco em regulação de comunicações em geral.

Abrimos este volume com uma introdução que vai além da identificação das temáticas constantes da publicação e dá sequência ao registro histórico do arcabouço normativo setorial e do correspondente contexto socioeconômico e político das telecomunicações no Brasil. O artigo introdutório também registra as principais discussões jurídico-regulatórias que marcaram o ano de 2016.

$\mathrm{O}$ presente número é aberto com artigo intitulado "Regulation of Telecommunications: The Choice Between Market and Regulatory Failures", de Dmitrii Trubnikov, sobre a caracterização da política regulatória europeia de telecomunicações como espécie de falha de governo, em virtude de modelagem 
regulatória voltada a criar oportunidades a certos grupos econômicos e impedir o ingresso ou a continuidade de outros. Trata-se de análise aprofundada do arcabouço regulatório para as comunicações eletrônicas frente aos objetivos políticos que as inspiraram.

Em seguida, no artigo intitulado "Implicações da declaração de invalidade da Diretiva 2006/24 na conservação de dados ("metadados") nos Estados-Membros da UE: uma leitura jusfundamental", Alessandra Silveira e Pedro Miguel Freitas promovem a uma percuciente análise da recente jurisprudência do Tribunal de Justiça da União Europeia sobre a conservação de dados por fornecedores de serviços de comunicações eletrônicas, em especial os efeitos do acórdão Digital Rights Ireland sobre o núcleo essencial do direito à privacidade e os limites impostos aos Estados-Membros de imporem medidas generalizadas e indiferenciadas de conservação de dados, embora possam adotar medidas de conservação seletiva de dados de tráfego e de localização com a finalidade de luta contra a delinquência grave.

José Albenez Bezerra Júnior, em seu artigo comparativo entre a arbitragem brasileira e a europeia, analisa as semelhanças e diferenças entre as práticas da ANATEL e da OFCOM para evidenciar as vantagens do método extrajudicial de resolução de conflitos no contexto de sua aplicação no Brasil.

O artigo de Oona de Oliveira Cajú, por sua vez, revisita a Arguição de Descumprimento de Preceito Fundamental 130/DF, que declarou a Lei de Imprensa brasileria como não-recepcionada pela Constituição Federal de 1988, para analisar a metalinguagem inscrita nos votos dos Ministros do Supremo Tribunal Federal, identificados como fortemente apoiados no paradigma libertariano do livre fluxo da informação.

Em sequência, no artigo intitulado "Dispositivos Eletrônicos Portáteis: Interferências nos instrumentos de comunicação e navegação das aeronaves", João Pedro França Santos e Roberto Márcio Santos analisam as interferências nos instrumentos de comunicação e navegação das aeronaves por dispositivos eletrônicos portáteis e mapeiam as várias reações regulatórias aplicadas a tais dispositivos.

Victor Oliveira Fernandes analisa, no artigo seguinte, as políticas de interconexão IP para suportes de serviços de voz na União Europeia a partir do enfoque das teorias do interesse público, que revelam, para além da busca pela eficiência alocativa, a concorrência efetiva e a neutralidade tecnológica.

No artigo intitulado "Regulação da Internet como Administração da Privacidade", Patricia Yuri Dias identifica aspectos da teoria responsiva da regulação como mecanismos utilizados por empresas privadas para administração do direito à privacidade na internet.

Finalmente, o último artigo deste volume da Revista de Direito, Estado e Telecomunicações intitulado "A Regulação Responsiva das Telecomunicações: 
Novos horizontes para o controle de obrigações pela Anatel", de autoria de João Marcelo Azevedo Marques Mello da Silva, identifica aspectos responsivos nas discussões de aprimoramento do modelo brasileiro de regulação das telecomunicações, na atuação fiscalizatória da Agência Nacional de Telecomunicações.

Segue-se, na última seção da revista, a reunião das normas e seleção de julgados jurisdicionais e administrativos do setor de telecomunicações do ano de 2016 organizados por temas e referenciados a tabelas informativas. Ao final, foi inserido um exaustivo índice alfabético e remissivo das normas e julgados do setor no ano de 2016. Cada tema presente em dita seção contém referências a normas de todos os níveis e a atos administrativos correlatos.

\section{O setor de telecomunicações no ano de $2016^{*}$}

Os primeiros meses do ano de 2016 transpareciam a certeza, que logo viria a ser abalada, de que o setor de telecomunicações seria deixado de lado eclipsado pela crise econômica e política em meio a escândalos de corrupção que viriam a derrubar a presidente da república Dilma Rousseff.

O plano plurianual (PPA) referente ao período de 2016 a 2019 foi aprovado pelo Congresso Nacional regularmente pela Lei 13.249, de 13 de janeiro de 2016. No detalhamento dos Programas Temáticos do Anexo I à Lei 13.249/2016, diversos objetivos do Programa de Comunicações para o Desenvolvimento, a Inclusão e a Democracia, foram elencados, abordando os objetivos de expansão do acesso à internet em banca larga para todos, promovendo o uso das Tecnologias da Informação e Comunicação, tendo por meta $(048 \mathrm{G})$ aumentar a velocidade média da banda larga fixa, $(048 \mathrm{H})$ aumentar a proporção de acessos da banda larga móvel (3G/4G) para $90 \%$ dos acessos móveis pessoais, (048I) ampliar a parcela da população coberta com rede de transporte (backhaul) óptica, (048J) alcançar 1 milhão de participantes pelos Programas de Inclusão Digital, (048K) implantar 262 cidades digitais, (048L) atender 11.000 áreas de vulnerabilidade digital com acesso à internet pelo Programa GESAC, e (04EC) disponibilizar o serviço de banda larga móvel em todos os municípios do país.

O PPA 2016-2019 também projetou o objetivo de viabilizar a implantação da TV Digital com inclusão social, tendo por metas (0481) a implantação da TV digital em 3.244 municípios, (0482) a distribuição de conversores digitais para os $100 \%$ dos domicílios beneficiários do Programa Bolsa Família e (0483) disponibilização gratuita de 24 aplicativos interativos de TV digital à população,

* O capítulo do setor de telecomunicações no ano de 2016 foi elaborado por Márcio Iorio Aranha. 
bem como ampliar os serviços de comunicação e expandir a radiodifusão com ênfase no Sistema Público, tendo por metas (048P) a ampliação do número de rádios e televisões educativas em 140 novas estações, das quais 72 na Região Nordeste e o restante distribuído pelas demais regiões do país, (048S) a ampliação do número de rádios comunitárias no país em 400 novas estações e (048R) a ampliação do número de geradoras de televisão comerciais em 55 novas estações. O PPA 2016-2019 também fixou o objetivo de incentivar a produção nacional e a distribuição de conteúdos digitais criativos, ampliar a produção e o acesso da sociedade a conteúdos multimídia, de natureza educativa, artística, cultural, informativa, científica e promotores da cidadania, ofertados de forma colaborativa pela Rede Nacional de Comunicação Pública, promover a inovação, o desenvolvimento tecnológico e a competitividade da indústria nacional de telecomunicações.

No âmbito do Programa de Defesa Nacional, o PPA 2016-2019 dispôs sobre a cooperação com o desenvolvimento nacional, defesa civil e ações governamentais em benefício da sociedade, adotando como Iniciativa 05TA o aprimoramento do uso da rede de telecomunicação via satélite na Amazônia.

No âmbito do Programa de Desenvolvimento da Indústria, Comércio e Serviços, o PPA 2016-2019, por sua vez, comprometeu-se a elevar a competividade, a qualidade e a produtividade da indústria brasileira por meio do investimento, da melhoria dos processos produtivos e da modernização do parque industrial, difundir e monitorar periodicamente o regime de redução temporária da alíquota do imposto de importação para bens de capital e bens de informática e telecomunicações (regime de Ex-Tarifário), e reduzir a burocracia e o prazo para sua concessão, por meio da implantação de sistema eletrônico.

Como de costume, entrentanto, o planejamento quinquenal da mais alta Casa legislativa do País foi publicado sem o acompanhamento de estudos que embasassem suas projeções.

No dia seguinte à edição do plano plurianual, as boas intenções dos Poderes de República começaram a ser minadas. A Lei 13.255, de 14 de janeiro de 2016, ao estimar a receita e fixar a despesa da União para o exercício financeiro de 2016, expressamente vinculou (art. $4^{\circ}$, XXII) a liberação de créditos suplementares do FUST e do FUNTTEL à obtenção da meta de superávit primário estabelecida para o exercício, ambos os fundos essenciais à consecução de várias medidas de universalização e avanço tecnológico das telecomunicações. A referência sequer mereceria ser aqui citada, haja vista a naturalização, pelos órgãos de controle brasileiros, do desvio dos recursos de fundos, desde que cumpridos certos requisitos formais de declaração expressa da intenção de desviar.

A ANATEL, por sua vez, construiu, por meio de arbitramento administrativo (Acórdão no 2/2016, que deu origem ao Ato do Conselho Diretor da ANATEL 
$\mathrm{n}^{\mathrm{o}} 50.004$, de 5 de janeiro de 2016), o rol de requisitos de projetos que poderiam ser executados como compromissos adicionais no âmbito de Termos de Compromisso de Ajustamento de Conduta (TAC), que já nessa época, havia se consolidado como a saída possível para o acúmulo descontrolado de sanções, que, chegavam a casa de dezenas de bilhões de reais para as concessionárias de telefonia fixa.

A implantação da TV digital seguiu o esperado ajuste de percurso, sem sobressaltos, quando o Decreto 8.753, de 10 de maio de 2016, alterou o Decreto 5.820/2006 no que concerne ao cronograma de transição analógico-digital, fixando o dia 31 de dezembro de 2018 como data limite para o encerramento da transmissão analógica em localidades nas quais fosse necessária a viabilização da implantação das redes de telefonia móvel $4 \mathrm{G}$ na faixa de radiofrequências de $698 \mathrm{MHz}$ a $806 \mathrm{MHz}$. Antes disso, a Portaria MC no 263, de 14 de janeiro de 2016, havia determinado a priorização das famílias inscritas no Cadastro Único para Programas Sociais (CadÚnico) para distribuição de set-top-boxes (caixas conversoras) para recepção do sinal de televisão digital no município de Rio Verde/GO, o primeiro município em que ocorreu o desligamento da transmissão analógica no Brasil.

Manteve-se, portanto, no âmbito do acompanhamento da transição analógico-digital, uma postura regulatória de metarregulação ao se preservar a atuação da Entidade Administradora da Digitalização (EAD), definindo-se o parâmetro de priorização da distribuição de caixas conversoras segundo política pública governamental.

Em outra frente, o Acórdão do Conselho Diretor da ANATEL, de 29 de janeiro de 2016 (Ref. $n^{\circ}$ 28/2016), aceitou pedido formulado pelas operadoras vencedoras da licitação dos $700 \mathrm{MHz}$ e, portanto, responsáveis pelo aporte de recursos ao processo de digitalização da TV aberta mediante liberação de frequências para o Serviço Móvel Pessoal em tecnologia 4G. Elas requeriam a postergação do aporte de recursos destinado ao ressarcimento dos custos decorrentes da redistribuição de canais de TV e RTV e das soluções para os problemas de interferência prejudicial nos sistemas de radiocomunicação, tendo em vista a alteração do cronograma de implementação da TV digital.

Outras duas portarias ministeriais agora do novo Ministério da Ciência, Tecnologia, Inovações e Comunicações (MCTIC) promoveram pequenos ajustes na regulamentação referente ao cronograma e requisitos da transmissão digital (Portarias MCTIC $n^{\circ} 3.493$ e $n^{\circ} 4.294$ ) e, finalmente, as primeiras homologações do encerramento da transmissão da programação das emissoras dos serviços de radiodifusão de sons e imagens e de retransmissão de televisão, em tecnologia analógica, no Brasil, ocorreram via portarias ministeriais editadas no segundo semestre de 2016. 
A mudança de direção do Executivo brasileiro surtiu efeitos imediatos na administração da Empresa Brasil de Comunicação (EBC), que havia sido criada com a previsão de mandato fixo de dirigentes e a figura de um Conselho Curador voltado a lhe dar a aparência de sistema público de radiodifusão. Falase em aparência, pois, de fato, os exemplos modelares de uma BBC inglesa ou de uma PBS norte-americana não serviram de guias para a criação da EBC. A Medida Provisória 744, de $1^{\circ}$ de setembro de 2016, após uma tentativa de alteração da presidência da EBC por Decreto presidencial, frustrada por liminar do Supremo Tribunal Federal, alterou a lei que autorizara a constituição da EBC (Lei 11.652/2008), desvinculando-a da Secretaria de Comunicação Social da Presidência da República para vinculá-la à Casa Civil daquele órgão, eliminando da estrutura da EBC a figura do Conselho Curador, incluindo um membro do Conselho de Administração indicado pelo Ministro de Estado da Educação, e eliminando a proteção de mandato fixo de quatro anos da Diretoria-Executiva para submetê-la à livre nomeação e exoneração pelo Presidente da República. A esboçada reação da presidência da entidade à ordem do novo Presidente da República foi finalmente afastada com a perda de objeto da ação então em andamento no STF, revogados os dispositivos legais que protegiam a o presidente da entidade da exoneração a qualquer tempo pela Presidência da República. O passo concomitante e natural, foi o de alteração do Estatuto Social da Empresa Brasil de Comunicações S.A. (Decreto 8.846, de $1^{\circ}$ de setembro de 2016). Embora a alteração de uma das únicas manifestações próximas ao ideal de TV pública tenha sido drástica, ela não era menos esperada, haja vista a estruturação inicial da entidade como uma longa manus do Estado, mais especificamente, do Poder Executivo federal, naturalmente suscetível à mudança do humor no cenário político, tanto mais quando a mudança se deu por meio de impeachment. A promessa não cumprida desde sua inauguração de constituição de uma TV pública de âmbito nacional foi definitivamente sepultada no segundo semestre de 2016.

Outras definições corriqueiras do setor seguiram o seu rumo esperado, como a disciplina da anuência prévia à reorganização societária do GRUPO TELEFÔNICA BRASIL, compreendendo a incorporação das empresas GVT PARTICIPAÇÕES S/A e GLOBAL VILLAGE TELECOM S/A pela TELEFÔNICA BRASIL S/A (Ato do Conselho Diretor da ANATEL n ${ }^{\circ} 50.169$, de 22 de janeiro de 2016).

As resoluções aprovadas pelo conselho diretor da ANATEL durante o ano de 2016 - onze no total - restringiram-se a alterações pontuais de regulamentos preexistentes, revogação do regulamento para certificação do cartão indutivo, com destaque, entretanto, para a Resolução n ${ }^{\circ}$ 671, de 3 de novembro de 2016, que aprovou o novo Regulamento do Uso do Espectro de Radiofrequências já sob o comando do novo presidente da ANATEL. 
O momento de tensão foi reservado à regulamentação tardia do Marco Civil da Internet (Lei 12.965, de 23 de abril de 2014), advinda do Decreto 8.771, de 11 de maio de 2016, aprovado um dia antes do afastamento provisório da presidente Dilma Rousseff.

\section{A ANATEL no estrelato: a revolta da franquia}

Em abril de 2016, quando já se encontrava formada a comissão para apreciação do pedido de instauração do processo de impeachment da presidente Dilma Rousseff no Senado Federal, em plena recessão econômica e crise política sem igual nos últimos 25 anos, após admissibilidade do processo de impedimento por mais de $2 / 3$ dos deputados federais, e ameaça de que, com a assunção do vice-presidente Michel Temer ao cargo de Presidente da República, o Ministério das Comunicações fosse extinto e fundido com a Secretaria de Comunicação da Presidência da República ou com o Ministério da Ciência, Tecnologia e Inovação, a ANATEL, ainda assim, ocupou o estrelato na mídia ao galvanizar a insatisfação popular com manifestação de seu então presidente, João Batista Rezende, sobre a possibilidade jurídica de implantação de franquias de dados nos planos de banda larga fixa após anúncio da Telefônica de que passaria, no ano seguinte, a limitar os pacotes de seu portfolio.

O uso de franquias já era uma prática regular de quase todas as operadoras móveis, exceto a TIM, e de duas operadoras de banda larga fixa, a Net e a Oi, mas a falta de tato na divulgação da medida pelo novo presidente da Telefônica, em franco processo de "gevetização", após aquisição da GVT, e consequente insensibilidade quanto à repercussão de sua fala, por parte do então presidente da ANATEL, disparou a reação de uma sociedade que reputava a regra das franquias como um atentado ao seu direito ao acesso à informação, tendo como pivô central o acesso às redes sociais.

A lógica então defendida pela superintendência de competição da Agência foi de que a franquia corrigiria uma falha de mercado ao fazer com que consumidores intensivos de banda pagassem sua parte, desonerando os consumidores de baixo consumo. A teoria da seleção adversa foi citada pelo superintendente de competição, Carlos Baigorri, para explicar que, como as empresas fixariam seus preços em uma média de uso mais alto, isso elevaria o preço pago pelos consumidores não intensivos, uma defesa, aliás razoável do que efetivamente dirige o discurso dos modelos de negócios empresariais. $\mathrm{O}$ Comitê Gestor da Internet no Brasil (CGI.br) posicionou-se por intermédio da resolução CGI.br/RES/2016/015, de julho de 2016, pela construção de soluções "que atend[essem] de forma equilibrada aos diversos segmentos atingidos" em franca tentativa de colocar panos quentes sobre o assunto. 
As associações de defesa dos consumidores e a sociedade em geral, entretanto, não compraram a ideia de benefício sistêmico, haja vista a evidência de que a Telefônica não havia esboçado qualquer intenção no sentido de redução de preço dos planos de dados, bem como ofertava planos com limites mensais bem inferiores aos praticados em outros países.

A reação parlamentar não tardou e ao final do mês de abril já tramitavam no Senado Federal quatro projetos sobre o tema da franquia da banda larga fixa. Três deles proibiam as operadoras de fixarem franquias de dados em seus contratos via: a) sustação de trecho do regulamento de Serviço de Comunicação Multimídia da ANATEL onde ele prevê a possibilidade de que os planos de serviço do SCM esclareçam as franquias de consumo, quando aplicáveis (art. 63, III e $\S \S 1^{\circ}, 2^{\circ}$ e $3^{\circ}$ do Regulamento do Serviço de Comunicação Multimídia, anexo à Resolução ANATEL n ${ }^{\circ}$ 614, de 28 de maio de 2013) por intermédio de Projeto de Decreto Legislativo PDS 14/2016; b) inserção de vedação da prática de franquias de dados na banda larga fixa no texto do Marco Civil da Internet (acréscimo do inciso XIV ao art. $7^{\circ}$ da Lei 12.965/2014), por intermédio dos Projetos de Lei do Senado PLS 174/2016 E PLS 176/201. Um quarto projeto de lei (PLS 175/2016), embora não proibisse a prática das franquias, estabelecia condicionamentos para aplicação de sobretaxas ou diminuição de velocidade de tráfego excedente a $50 \%$ da velocidade máxima contratada e somente em horários de pico na rede. Em agosto de 2016, já havia 25 projetos de lei sobre franquias em andamento no Congresso Nacional.

O que se evidencia desse acontecimento é o fato de que a internet é uma candidata cada dia mais forte à regulação. A ausência de uma acompanhamento conjuntural da demanda média de consumo da banda larga, dos programas de governo de universalização da infraestrutura de acesso à internet, da qualidade dos serviços e das relações de neutralidade entre os atores responsáveis pela viabilização da internet não significa menor interferência estatal no setor.

O atropelo causado pela divulgação pouco pensada sobre a implantação, em larga escala, de franquias de dados da banda larga fixa no Brasil no início de 2016 revelou um movimento no sentido de limitar as opções comerciais por leis estáticas. O modelo regulatório da internet não deveria ser um modelo de intromissão estatal na atividade, mas de preservação da dinâmica da internet no meio regulado.

\section{Solução para o STFC: do regime público para o privado}

O título desta seção poderia ter sido o novo modelo de telecomunicações inaugurado pela lei de número tal, mas devido a questionamentos da oposição ao trâmite parlamentar do projeto de lei de alteração da Lei Geral de Telecomunicações, voltado a, em grande parte, viabilizar a transformação das 
concessões de Serviço Telefônico Fixo Comutado em autorizações de STFC, o ano de 2016 finalizou com uma dúvida sobre se o processo legislativo teria sido suspenso ou se os recursos interpostos pela oposição à Mesa do Senado teriam efetivamente sido negados, com o consequente encaminhamento do autógrafo para sanção presidencial. Os primeiros dias de 2017 esclareceram que a presidência do Senado ainda se pronunciaria sobre os recursos e a lei que redefiniria um dos pilares do novo modelo regulatório, ao reservar o regime público a situações excepcionais, entre outras alterações do arcabouço normativo setorial, foi deixada para 2017.

O segundo semestre de 2016 foi palco de renovadas esperanças para a ANATEL, que recebeu, pela primeira vez em sua história, um ex-ministro das comunicações - Juarez Quadros - para sua presidência, empossado no dia 6 de outubro de 2016 para um mandato até 4 de novembro de 2018.

Sua chegada na agência reguladora ocorreu precisamente no momento em que um dos pilares do modelo regulatório das telecomunicações brasileiras estava em vias de ser alterado: trata-se da coexistência de concessões de STFC e autorizações de STFC e outros serviços de telecomunicações em sentido estrito.

A persistência das concessões ainda se apresentava como uma solução de compromisso entre um passado de prestação estatizada de serviços previamente à Emenda Constitucional no 8/1995 e consequente Lei Mínima de 1996 e Lei Geral de Telecomunicações de 1997, e o novo modelo de convivência entre serviços submetidos a regime de direito público e privado.

De um lado, o regime público bebe das características clássicas atribuídas à prestação de serviços públicos, quais sejam, os conceitos de atividade normatizada, de obrigatoriedade da prestação do serviço, de continuidade garantida pelo Estado, de generalidade na organização do serviços, ou universalização na terminologia regulatória do setor, de modificação unilateral das normas de organização do serviço, de manifestação do poder de autoridade, de eficiência e qualidade, de responsabilidade objetiva, de modicidade tarifária e de afetação ao interesse público de bens essenciais à prestação do serviço.

De outro lado, o regime privado teria os princípios da ordem econômica concorrencial do art. 170 da Constituição Federal aplicáveis em sua plenitude, inexistente controle de preços cobrados dos consumidores, a própria figura do usuário seria afastada, haveria limites à modificação unilateral das normas de organização do serviço, por natureza, de prestação facultativa, ausentes obrigações de universalização ou de continuidade garantida pelo Estado.

Esse desenho tradicional de separação estanque entre regimes público e privado dos serviços de telecomunicações foi sendo minado muito mais pelo incremento de atos administrativos regulatórios unilaterais no regime privado do que pela corrosão do regime público, que permaneceu incólume em seus pilares fundamentais de generalidade na organização do serviço (universalização) e 
afetação de bens reversíveis. Aliás, o setor de telecomunicações foi um dos únicos setores em que houve um esforço dos órgãos de controle, em especial do Tribunal de Contas da União e de uma associação de defesa do consumidor (ProTeste), em fomentar a discriminação específica de todos os bens afetados ao serviço, com descrição dos valores correspondentes. Uma ação civil pública da ProTeste de 2011 obteve decisão favorável do TRF da $1^{\text {a }}$ Região, em março de 2016, quanto à disponibilização ao público em geral do inventário de bens reversíveis em poder das operadoras de STFC em regime público. Em dezembro de 2015, por sua vez, o TCU determinou à ANATEL que apurasse os valores obtidos pelas concessionárias de STFC com a alienação de bens reversíveis. Em julho de 2016, em apreciação de recurso da ANATEL contra vários pontos da decisão, o TCU reafirmou que bem reversível é o essencial para a prestação do serviço e determinou que a Agência, no prazo de 180 dias, encaminhasse a lista de todos os bens reversíveis já vendidos pelas concessionárias desde 25/01/2007, data de início da vigência do regulamento de controle de bens reversíveis.

Foi também em meados de 2016 que o Brasil presenciou o início da maior recuperação judicial de sua história pedida pela concessionária de STFC, Oi, após o insucesso da negociação de uma dívida de cerca de $\mathrm{R} \$ 64,5$ bilhões com seus credores, entre eles a própria ANATEL, para os quais declarara dias antes uma listagem de imóveis constitutivos dos ativos da empresa, em que 98\% deles vinham classificados pela própria empresa como bens reversíveis. Trata-se de pedido de recuperação judicial equivalente à concordata da operadora Oi, em junho de 2016, por parte de seus controladores Oi S.A., Telemar Norte Leste S.A., Oi Móvel S.A.,Copart 4 e 5 Participações S.A., Portugal Telecom International Finance B.V. e Oi Brasil Holding Coöperatief U.A na primeira instância da Justiça Estadual do Rio de Janeiro (Processo $\mathrm{n}^{\circ}$ 020371165.2016.8.19.0001).

A reação da Agência logo após a instauração do processo de recuperação judicial foi o de emitir um Acórdão 232/2016 com determinações de que a Oi, suas controladoras e controladas, se abstivessem de alienar bens móveis e imóveis sem a anuência prévia do órgão regulador.

A operadora Oi reunia todos os ingredientes para figurar como bastião do orgulho nacional. Ela é ainda a única grande empresa de capital nacional derivada da privatização do antigo Sistema Telebras, que foi criado e gerido durante o Regime Militar de 1964 a 1985 e, ao menos durante a década de 1970, reconhecido pelo profissionalismo de seu presidente, o General Alencastro, tido como o grande responsável pela estruturação da rede nacional de telecomunicações brasileira.

A Oi surgiu como produto da aquisição da Brasil Telecom pela Oi/Telemar, reunindo em uma só empresa a infraestrutura básica herdada do 
Sistema Telebras de todo o território brasileiro exceto o Estado de São Paulo e expandida durante os últimos 18 anos de atuação privada. Trata-se das duas maiores regiões leiloadas durante a privatização do Sistema Telebras. Não à toa, a Oi usufruiu o título de maior operadora de telefonia fixa do País, embora nunca tivesse conseguido se equiparar às demais operadoras na telefonia móvel. Mesmo sua posição sobranceira no mercado em declínio da telefonia fixa já estava sendo contestada. Em três anos, do início de 2013 ao final de 2015, seu participação no mercado de telefones fixos em serviço caiu assustadores 7,3 pontos percentuais de $42 \%$ para $34,7 \%$, enquanto o Grupo Vivo da Telefônica e o Grupo Claro da Telmex passaram respectivamente, de $32 \%$ para $34,38 \%$ e de $21,9 \%$ para 26,8\%, mantendo-se nesse patamar em 2016. Ainda mais revelador do descompasso de planejamento e investimento da Oi era o setor de telefonia móvel. A par do fiasco em sequer concorrer à faixa de frequência de $700 \mathrm{MHz}$ para implantação de 4G leiloada em 2014, os números da Oi falam por si sós. Enquanto as operadoras Vivo (Telefônica), Claro (Telmex) e TIM encontravamse, no início de 2016 , na faixa de $25 \%$ a $28 \%$ de market share, a Oi caminhava isolada com cerca de $18 \%$ de market share. Não fosse o fato da Oi ser herdeira da infraestrutura de rede local de praticamente todo o território nacional, exceto troncos interestaduais e internacionais e o Estado de São Paulo, o cenário bem que poderia ser motivo de aplausos em termos concorrenciais. A partir de 2002, a lógica das regiões não se aplicava mais à regulação de telecomunicações no Brasil, estando as concessionárias autorizadas a ingressarem nas regiões antes reservadas a cada vencedor dos leilões da privatização. A compreensão desse histórico é, entretanto, fundamental para se entender a posição de destaque gozada pela Oi.

A razão da divisão do País em regiões foi justificada, quando da aprovação da Lei Geral de Telecomunicações de 1997, durante o Governo FHC (Fernando Henrique Cardoso), no desígnio de criação de um ambiente concorrencial equilibrado. Três regiões regeram a sistemática de leilões do Sistema Telebras além de um leilão específico para a exploração de ligações interestaduais e internacionais. A região sob controle da subsidiária da Telebras chamada Tele Centro Sul foi levada pela Brasil Telecom no leilão de 1998 e abarcava os Estados da Região Sul do País, Centro-Oeste e alguns Estados da Região Norte do Brasil. A Telemar, depois renomeada para Oi, adquiriu a infraestrutura e a concessão para exploração da região ocupada pela Tele Norte Leste, correspondente a outra região que abarcava os Estados do Nordeste do Brasil, os demais Estados do Norte do País além dos Estados do Rio de Janeiro, Espírito Santo e Minas Gerais, no Sudeste do País. Os outros dois grandes atores setoriais que surgiram da privatização do Sistema Telebras foram a Telefônica de Espanha, hoje representada pelo emblema comercial Vivo, que adquiriu a região correspondente ao Estado de São Paulo e a MCI World Com, que 
adquiriu a Embratel no leilão da Telebras conjuntamente com os direitos de exploração de ligações internacionais e interestaduais, mais tarde adquirida, em 2004, pela Telmex com a falência da WorldCom em 2002 e que hoje faz parte do grupo Claro.

Como se pode ver, o sistema detinha uma lógica de divisão de mercados por PIB, segundo dados do ano de 1997: a Tele Norte Leste, adquirida pela Oi/Telemar, abarcava uma região de maior extensão geográfica correspondente a 39\% do PIB brasileiro; a Tele Centro Sul, adquirida pela Brasil Telecom, abarcava uma região com menores obstáculos à infraestrutura, mas ainda com grande extensão territorial, correspondendo a 25\% do PIB; a Telefônica, por sua vez, adquiriu a joia da coroa, que foi o Estado de São Paulo, uma região que concentrava 36\% do PIB no Estado de maior densidade populacional do Brasil.

Diante desse cenário, algumas conjecturas podem ser apresentadas. A primeira delas diz respeito ao formato de divisão inicial das regiões quando das privatizações de 1998, em que a entrega de duas regiões de grande extensão geográfica frente a uma região com grande concentração de renda em pequena extensão geográfica parece ter criado uma incompatibilidade intestina entre os custos de infraestrutura, resultando na junção das duas maiores regiões anos mais tarde sob o argumento de contrabalancear as vantagens comparativas da empresa sediada no Estado de São Paulo, a Telefônica, hoje Grupo Vivo.

$\mathrm{O}$ argumento de que a Oi estaria fadada ao fracasso por ter herdado um osso duro de roer ao se comprometer com metas de expansão que englobavam os Estados do norte do País, inclusive grande parte da Floresta Amazônica, somente teria ressonância nos dias de hoje se em 2002 as fronteiras entre as regiões de concessão não tivessem sido relaxadas. De lá para cá, esse argumento de responsabilidade social esfumaçou-se, embora ela ainda carregue as obrigações de universalização em regiões flagrantemente onerosas devido ao regime de concessão de serviço telefônico fixo comutado que ostenta e que a ANATEL já declarara a intenção de extinguir a depender de política pública governamental.

O modelo de privatizações apoiou-se em uma ilusão fundamental de que o equilíbrio entre os lotes dos leilões da Telebras, ao deterem PIBs semelhantes, seriam suficientes para resultarem em igualdade de condições concorrenciais, mesmo que o PIB da região abarcada pela Oi de hoje fosse pulverizado em uma área geográfica mais de 34 vezes maior que a da concorrente Telefônica/Vivo. Para uma indústria apoiada em infraestrutura de redes com interconexão garantida pelo Estado, foi, de fato, uma opção infeliz. Essa conjectura de desvantagem originária do modelo concorrencial serve apenas para o fim de se evidenciar que equilíbrio concorrencial não é sinônimo de saúde concorrencial, e que o momento histórico das privatizações poderia ter optado por outro caminho. Por exemplo, poder-se-ia ter optado por leilão da infraestrutura de 
redes a um ator setorial, e.g., a Embratel de então, combinado com concessões de serviços de telecomunicações às demais empresas, competindo à agência reguladora principalmente o controle do mercado de vendas de atacado. Isso teria antecipado as inúmeras dificuldades hoje enfrentadas pelo regulador brasileiro de conjugação entre a política regulatória da banda larga e dos demais serviços de telecomunicações, em especial, a telefonia fixa. Mas voltemos à nua e crua realidade.

Uma segunda conjectura que tem granjeado adeptos no setor é a de que a progressiva deterioração da Oi estaria associada a alegados interesses inconfessáveis de políticos desde o assento presidencial até outras esferas funcionais de poder. O enfrentamento de problemas estruturais, de gestão e de reestruturação empresarial teriam sido postergados por exigência de atores do alto escalão da República, que, a pretexto da realização de operações de salvamento da empresa nacional, estariam avançando interesses escusos. A possibilidade de tal ocorrência se deve ao fato de que estudos do setor demonstram a cadeia de controle societário da então Telemar dominada por empréstimos governamentais via BNDES. A efetiva submissão da empresa aos sabores e dissabores governamentais, entretanto, somente pode se justificar em virtude da constante dependência empresarial de benesses governamentais, em que alterações do marco regulatório brasileiro no interesse da empresa fossem respostas ou sintomas dessa proximidade indesejável. Em síntese, fosse uma ou outra a causa, ou ambas, essa via de ingerência governamental na empresa não explicaria, por si só, as falhas de gestão e de estratégia empresarial, mas tão somente a abertura de espaço a relações espúrias com titulares de cargos públicos acusados de apropriação privada de benefícios públicos.

Uma terceira conjectura dirige-se a uma postura governamental de inação política ao postergar medidas necessárias à ampliação da concorrência e atualização do setor à novas demandas. A disciplina legal brasileira, embora tenha caminhado com o tempo para atualizar a legislação de TV por assinatura, de regulação do conteúdo audiovisual, de convergência regulamentar em termos de usuários e serviços, não deixou espaço à atualização normativa do Serviço Telefônico Fixo Comutado (STFC), que permaneceu regido por velocidades incompatíveis com a banda larga.

Ao não permitir a atualização do regime jurídico do STFC às demandas sociais e de negócio da banda larga, o Governo federal manteve reféns as maiores empresas de telecomunicações do País, mas a regulamentação da agência reguladora abriu outros caminhos para prestação de banda larga via autorizações de Serviço de Comunicação Multimídia (SCM).

Por isso, a rigidez de regime do STFC somente explica a limitação legal à convergência de serviços e, mesmo assim, em ambiente institucional em que as concessionárias podem também obter autorizações de serviços de telefonia 
móvel, banda larga e TV por assinatura, o que evidencia que as amarras regulatórias à expansção do STFC atingem somente o STFC e todas as concessionárias de modo equânime, não fosse a dimensão territorial das obrigações de universalização da Oi consideravelmente maiores que as de suas rivais.

De fato, não se pode atribuir a derrocada empresarial somente à rigidez de regime jurídico do STFC, mas não se pode olvidar que a preservação do STFC sob o manto de estrito controle presidencial revela um mecanismo de constante dependência empresarial das opções de Governo, inclusive no tocante às dificuldades que a figura dos bens reversíveis gera para a empresa na captação de recursos no mercado. Ao se gravar os bens essenciais à prestação do STFC como reversíveis, a empresa deixa de poder dar em garantia tais bens para fins de contratação de empréstimos, o que eleva seu custo operacional e o ônus da gestão empresarial.

As dificuldades da Oi escancaradas no pedido de recuperação judicial de 2016 não necessariamente decorrem do regime de direito público, mas certamente têm relação com o isolamento do regime regulatório aplicado por cima do regime de direito público e que impediu a atualização do STFC às novas demandas sociais.

Não por acaso, analistas do setor concordaram, majoritariamente, na inadequação do regime à prestação do Serviço Telefônico Fixo Comutado e advogaram, durante anos, pelo seu abandono para que, afinal, os serviços de telecomunicações em sentido estrito relevantes fossem prestados em regime de direito privado por intermédio do instrumento de autorização de serviços.

O tema da mudança de regime já estava sendo gestado na ANATEL há muito tempo e em fevereiro de 2016, um dos conselheiros, Igor Freitas, chegou a propor que o regime público do STFC ficasse restrito às áreas onde o serviço de voz fosse coberto somente por orelhões, restringindo sobremaneira o alcance do STFC em regime público em uma tentativa de contornar a dicção da LGT de que ao menos o STFC fosse submetido ao regime público. A proposta, entretanto, enfrentou resistências dentro e fora da ANATEL e o assunto somente voltou a caminhar em consonância com o projeto de lei de alteração da LGT de migração das concessões de STFC para o autorizações de serviço.

O novo governo pós-impeachment, com o agora presidente Michel Temer, assumiu sob o discurso da eficiência da máquina estatal e enxugamento das finanças públicas. A maior recuperação judicial da história brasileira da maior prestadora de STFC do país, a empresa Oi, também reputada um bastião da indústria nacional preservada durante da privatização da Telebras, em 1997, somado à demanda das demais operadoras e de atores do setor por uma solução definitiva ao embrólio dos bens reversíveis de um serviço que cada vez mais era menos desejado pela população, foram ingredientes suficientes para que o 
Projeto de Lei 3.543/2015, originária da Câmara dos Deputados, que autorizava a transformação das concessões em autorizações de STFC, tramitasse no Congresso Nacional com expresso apoio da Presidência da República.

A autorização de serviços como instrumento que reinaria sobranceiro no setor de telecomunicações em sentido estrito não viria, entretanto, sem percalços. A ANATEL até mesmo se antecipou à aprovação do PLC 79/2016, encaminhado ao Senado Federal após a aprovação do PL 3.543/2015 em 29 de novembro de 2016, na Câmara dos Deputados. Em 15 de dezembro de 2016, o conselho diretor da ANATEL aprovou proposta de consulta pública do Plano Geral de Outorgas para fixação das diretrizes de alteração do modelo setorial para 2017 com enfoque na migração das concessões de telefonia fixa para autorizações.

No Senado, a oposição, agora capitaneada por segmento do Partido dos Trabalhadores, interpôs pedido de que o projeto fosse votado pelo plenário da Casa, mesmo em contradição com outro segmento do PT, capitaneado pelo Senador Jorge Viana, que articulara a retirada de duas assinaturas do recurso para que o projeto fosse aprovado de forma terminativa nas comissões.

Em 19 de dezembro de 2016, noticiários especializados do setor de telecomunicações divulgaram que a Mesa do Senado teria indeferido os recursos apresentados ao PLC 79/2016, possibilitando que o projeto fosse diretamente para sanção presidencial sem a leitura do texto para votação no plenário da Casa, tendo sido aprovado em caráter terminativo na Comissão Especial de Desenvolvimento Econômico. O efetivo encaminhamento à Presidência da República, entretanto, permaneceu no limbo durante as festas de final de ano, enquanto onze senadores da oposição impetravam mandado de segurança contra o indeferimento do recurso ao PLC 79/2016, que aguardava liminar do ministro do STF, Teori Zavascki. O ministro do STF requereu informações à Mesa do Senado sobre o processo e o indeferimento dos recursos no Senado, respondido pelo advogado-geral do Senado, no dia 30 de dezembro de 2016, com a informação correta de que não teria havido deliberação formal da mesa diretora do Senado sobre os recursos interpostos pela oposição, protraindo o encaminhamento do projeto de lei para a sanção presidencial, mas antecipando que requisitos regimentais não teriam sido seguidos nos recursos apresentados pela oposição.

A solução para o STFC acenada pela PLC 79/2016 foi a de migração do regime público para o privado, mas não qualquer privado: um privado regulado. 


\section{Vídeo sob Demanda (VOD), Zero Rating e Neutralidade de Rede}

Enquanto a ANATEL caminhava no sentido de consolidar o regime jurídico prioritário de direito privado no setor de telecomunicações stricto sensu, a ANCINE avançava sobre a proposta de regulamentação do Vídeo sob Demanda (VOD), desde a aprovação de um documento de consolidação de visão sobre os "Desafios da Regulamentação do Vídeo sob Demanda" em 17 de dezembro de 2015, até a submissão de consulta pública, no dia 23 de dezembro de 2016, de uma notícia regulatória sobre a oferta de vídeo sob demanda ao consumidor brasileiro, definindo obrigações aos Serviços de Vídeo sob Demanda e às Plataformas de Compartilhamento de Conteúdos Audiovisuais em clara segmentação entre os conceitos de serviços e de infraestrutura de armazenamento de catálogos de conteúdos audiovisuais.

Na linha da separação, no Brasil, entre as competências da ANATEL sobre os serviços de distribuição e da ANCINE, sobre a etapa de programação/empacotamento, o VOD tem se consolidado em bases sólidas fora do alcance do regulador de telecomunicações stricto sensu.

Em outra frente regulatória sobre mecanismos de zero rating, ou seja, de desconto ou liberação de cobrança pelo streaming de vídeos, músicas ou acesso a certos aplicativos, em especial, de redes sociais, como o Facebook e o Whatsapp, a autoridade reguladora holandesa - Autoriteit Consument \& Markt (ACM) - proibiu, no início de 2017, a prática do zero rating pela T-Mobile por alegada violação das regras relativas à neutralidade de rede.

No Brasil, a neutralidade de rede foi erigida à condição de princípio de uso da internet (art. 3․ IV da Lei 12.965/2014, Marco Civil da Internet) e mereceu uma seção própria e inaugural do capítulo sobre a provisão de conexão e de aplicações de internet. A lei de 2014 determinou que o responsável pela transmissão, comutação ou roteamento tem o dever de "tratar de forma isonômica quaisquer pacotes de dados, sem distinção por conteúdo, origem e destino, serviço, terminal ou aplicação" (art. 9 ${ }^{\circ}$, caput da Lei 12.965/2014), remetendo os casos de discriminação ou degradação do tráfego a regulamentação por decreto presidencial. Trata-se de uma reserva regulamentar qualificada pelas hipóteses definidas em lei. Ou seja, a neutralidade de rede impõe tratamento isonômico de pacotes de dados, mas faculta a diferenciação dos pacotes por razões técnicas indispensáveis à prestação adequada dos serviços e aplicações ou para priorização de serviços de emergência (art. $9^{\circ}, \S 1^{\circ}$, I e II da Lei 12.965/2014).

A regulamentação do Marco Civil da Internet somente foi aprovada mais de dois anos depois da publicação da lei e, mesmo assim, às vésperas do afastamento presidencial que resultou no impeachment da presidente Dilma Rousseff. O Decreto 8.771, de 11 de maio de 2016, disciplinou as hipóteses 
admitidas de discriminação de pacotes de dados na internet e de degradação de tráfego, bem como regulamentou os procedimentos para guarda e proteção de dados por provedores de conexão e de aplicações, as medidas de transparência na requisição de dados cadastrais pela administração pública e os parâmetros para fiscalização e apuração de infrações. Ao fazê-lo, o Decreto 8.771/2016 acrescentou a orientação de que o tratamento isonômico de pacotes de dados devesse garantir a preservação do caráter público e irrestrito do acesso à internet (art. $3^{\circ}$, caput, do Decreto 8.771/2016). Para uma tradição de sistema jurídico que costumava equiparar o público à condição de atributo ou propriedade estatal, não deve restar dúvidas de que o direito brasileiro já não obedece à equivalência entre público e estatal, mas guiado por princípios de direito público, mesmo que de propriedade ou gerência privada.

Ainda, a regulamentação da neutralidade de rede qualificou a discriminação ou a degradação de tráfego como medidas excepcionais (art. $4^{\circ}$, caput, do Decreto 8.771/2016). No caso de estarem apoiadas em requisitos técnicos indispensáveis à prestação adequada de serviços e aplicações, tais medidas devem se restringir a manter a estabilidade, segurança, integridade $e$ funcionalidade da rede do responsável pelas atividades de transmissão, de comutação ou de roteamento.

A consideração da saúde da rede como um todo, ao invés da rede específica de cada responsável por atividades de transmissão, de comutação ou de roteamento, somente foi abordada de forma reflexa no regulamento do Marco Civil da Internet, ao se definirem os requisitos técnicos suficientes à discriminação ou degradação de tráfego como aqueles decorrentes de tratamento de questões de segurança de redes ou tratamento de situações excepcionais de congestionamento de redes, mediante elenco exemplificativo - expressamente não exaustivo - de questões de segurança, quais sejam, restrição ao envio de mensagens em massa (spam) ou controle de ataques de negação de serviço, e de congestionamento de redes, quais sejam, interrupções da rota principal de comunicação em situações de emergência.

Nenhum método direto de atuação concertada dos responsáveis pela transmissão, comutação ou roteamento das redes para preservação da saúde da internet como um todo foi introduzido na regulamentação, evidenciando a preocupação governamental com a relação estrita entre usuários das redes e os responsáveis pela transmissão, comutação ou roteamento. A imagem da internet como uma unidade que merece proteção especial enquanto tal perdeu importância para uma abordagem individualizada de atores específicos no interesse de preservação da saúde técnica de cada rede, sem uma preocupação com a saúde técnica da rede das redes, sob o fundamento implícito de que ela decorreria automaticamente da preservação de suas partes. 
A narrativa governamental consciente ou inconsciente sobre o bem a ser protegido pela neutralidade de rede foi capturada pelos interesses e direitos das partes atuantes na internet, o que é natural, abrindo-se mão da narrativa de preservação do meio de exercício das liberdades como bem maior a ser protegido. Em outras palavras, a regulamentação perdeu a oportunidade de identificar a internet como instituição garantida e garantidora dos direitos nela viabilizados ou potencializados para se prender em relações pontuais identificadas pela utilidade que cada rede presta a seus usuários.

O setor está caminhando para a hora da verdade: de um lado, a neutralidade de rede tem sido utilizada como pomada milagrosa para todos os males, isolando a gestão da rede de telecomunicações de promoções e ofertas e, portanto, servindo de argumento para se institucionalizar um modelo regulatório impermeável à concorrência, mediante afirmação da imunidade antitruste sobre a gestão da rede, ou das redes como prefere a disciplina normativa do setor; de outro lado, a neutralidade de rede pode vir a ser melhor trabalhada como um conceito próprio à vedação de discriminação na rede, sem que isso inviabilize a vocação concorrencial de ofertas com acesso facilitado a certas utilidades ou conteúdos, deixando-se o juízo sobre a proibição de práticas de gestão da rede de telecomunicações para a análise conjuntural e mais precisa de prejuízo efetivo à concorrência.

$\mathrm{O}$ mesmo raciocínio aplica-se à franquia de dados, quando a opção em voga por defensores da liberdade de acesso à internet é a da vedação apriorística de qualquer mecanismo de limitação de uso, sob o fundamento também apriorístico de que a medida teria por fundamento o desejo impudico de exploração do consumidor, ao invés de se abraçar o controle conjuntural das medidas de franquia a partir de análise regulatória propriamente dita, tanto de ordem setorial consumerista e técnica, quanto de ordem antitruste, na defesa da concorrência, o que manteria abertas as portas para o contínuo posicionamento social sobre os reais efeitos das opções regulatórias sobre franquia de dados.

\section{Joint venture entre o SBT, Record e Rede TV}

Em outra frente, as fronteiras sensíveis entre os reguladores foram testadas no embate entre emissoras de TV aberta e pacotes de TV paga na jointventure entre o SBT, Record e Rede TV (Ato de Concentração conhecido como NEWCO). De um lado, parecer do Conselheiro da ANATEL, Aníbal Diniz, aprovado em circuito deliberativo em fevereiro de 2016, em resposta a questionamento do CADE sobre a operação, entendeu que o licenciamento comercial conjunto de programação digital para operadoras de TV paga poderia equilibrar a relação das emissoras de TV aberta com a Net e Sky, que detinham $80 \%$ do mercado, mas provavelmente dificultaria o acesso ao conteúdo 
audiovisual da TV aberta por parte das pequenas empresas de TV paga. Muito embora a Lei 12.485/2011, do Serviço de Acesso Condicionado, previsse a possibilidade de contraprestação às emissoras comerciais abertas pela entrega da programação para o SeAC, como também garantisse o carregamento da programação gratuitamente caso não se alcançasse um acordo comercial, a critério das emissoras, é precisamente a aquisição do conteúdo audiovisual a principal barreira à entrada no mercado de TV paga, o que indicaria, no entender do conselho diretor da ANATEL, que a joint venture promoveria o aumento do preço dos pacotes, também tendo em vista a falta de transparência dos contratos de negociação de conteúdos, em face de decisão judicial que suspendeu a obrigação das empacotadoras de apresentarem todos os contratos mantidos com as programadoras à ANCINE.

Como se pode ver, o devido equacionamento de uma questão regulatória fundamental de equilíbrio de mercado depende de ajuste fino entre emissoras de radiodifusão, operadoras de SeAC dominantes e novas entrantes, a agência reguladora da etapa de distribuição do serviço (ANATEL), a agência reguladora da etapa de programação/empacotamento do conteúdo audiovisual (ANCINE), do órgão de controle da concorrência (CADE) e do Judiciário. Nesse caso, em particular, a disfunção é evidente. Enquanto ANATEL e ANCINE preocupam-se com a transparência e equilíbrio dos atores de mercado, o Judiciário preocupa-se com a consideração formal de poderes públicos do regulador e o CADE com aspectos concorrenciais de mercado relevante, atos de concentração, poder compensatório e ancilariedade. $\mathrm{O}$ conjunto desses olhares deveria fornecer uma solução concertada, não fosse o fato de que, em geral, são atores que fazem voo solo.

\section{Fundos Setoriais para Finalidades Alheias}

Enquanto o País tentava novamente controlar a economia desgastada pela crise gerada durante a administração da presidente Dilma Rousseff e dos escândalos agora noticiados mundialmente como um dos maiores esquemas de corrupção já existentes, os fundos setoriais continuavam gerando superávit primário sem repercussão no funcionamento da ANATEL, que, no ano de 2015, dos cerca de 5 bilhões de reais arrecadados pelo Fistel, detinha um orçamento que não chegava a $15 \%$ desse valor.

Em audiência pública na Comissão de Ciência e Tecnologia, Inovação, Comunicação e Informática do Senado, de 14 de dezembro de 2016, a representante do Ministério Público e presidente da Associação Nacional do Ministério Público do Consumidor, Alessandra Marques, defendou que o contingenciamento poderia ser entendido como crime de responsabilidade, algo, 
entretanto, na contramão do que se institucionalizou na jurisprudência do STF e do TCU a esse respeito.

O TCU, por sua vez, orientara a ANATEL a evidenciar ao governo o montante que a Agência utilizaria nos próximos cinco anos com o fito de evitar contingenciamento desses recursos e viabilizar que se exigisse do governo o uso justificado do restante.

Somente em 2016, mais precisamente em 4 de agosto de 2016, e por determinação do TCU, iniciou-se o processo de encontro de contas entre a ANATEL e a Secretaria do Tesouro Nacional, haja vista divergências quanto à arrecadação e saldos do FISTEL e FUST.

Até então, a ANATEL contabilizava para o FISTEL, entre 1997 e junho de 2015, uma arrecadação de $\mathrm{R} \$ 67,2$ bilhões e um saldo financeiro, em junho de 2015, de $\mathrm{R} \$ 64,8$ bilhões, correspondente à diferença entre o que efetivamente havia sido arrecadado e utilizado pela Agência, destinatária legal dos recursos das taxas de fiscalização do setor de telecomunicações. Em agosto de 2016, a Agência corrigiu os valores para $\mathrm{R} \$ 82,3$ bilhões de arrecadação do FISTEL no período e de meros R\$ 18,915 bilhões de saldo em junho de 2015 . Por sua vez, a Secretaria do Tesouro Nacional apontava uma arrecadação do FISTEL de R \$ 82,2 bilhões no mesmo período e um saldo em junho de 2015 de $\mathrm{R} \$ 15,4$ bilhões, admitindo o uso de $\mathrm{R} \$$ 51,5 bilhões em despesas diversas.

O FUST, por sua vez, que praticamente não fora tocado, exceto para projeto destinado a acessibilidade da telefonia conseguido a duras penas pela Agência, teria arrecadado, segundo a ANATEL, entre 2001 e 2015, R\$ 19,4 bilhões e teria o mesmo saldo em junho de 2015. O Tesouro Nacional discordava desses dados e informava ao TCU o valor de R\$16,04 bilhões de arrecadação no período e de $\mathrm{R} \$ 4,72$ bilhões de saldo em 2015, com $\mathrm{R} \$ 2,22$ bilhões empenhados em despesas identificadas e R\$ 8,92 bilhões, em despesas não identificadas. Em 4 de agosto de 2016, a ANATEL divulgou os números revisados do FUST para R\$ 17,6 bilhões de arrecadação entre 2001 e 2015 e saldo em 2015 de R \$ 4,73 bilhões. A partir dessas declarações, o TCU deu prazo para que a Agência e a Secretaria do Tesouro Nacional promovessem à conciliação dos valores de arrecadação, aplicação e saldo dos dois fundos setoriais.

Mais de quinze anos se passaram para que o TCU deixasse claro e, mesmo assim, sem averiguação concreta independente, senão por declaração do Tesouro e da Agência, os valores arrecadados, aplicados e saldos financeiros dos fundos FUST e FISTEL. Os saldos fictícios que a Agência divulgava para a sociedade tinham, por óbvio, a função de evidenciar o montante assustador de valores desviados da finalidade definida nas leis de criação do FUST e FISTEL. Somente agora poder-se-á averiguar quanto de cada fundo merece ser qualificado de desvio ou de aplicação legítima. Não há, entretanto, justificativa 
plausível para quinze anos de atraso na utilização integral dos recursos do FUST em sua função expressa de universalização dos serviços de telecomunicações, senão pela consciência dos atores do setor de telecomunicações da evidente desconexão entre a previsão legal de aplicação do fundo em serviços sob o regime público - o STFC - e a demanda social por serviços que não eram previstos na lei - SCM (banda larga fixa) e SMP (na sua dimensão de banda larga móvel). Esse talvez seja o mais contundente exemplo de como uma legislação bem intencionada acabou por inviabilizar o uso de recursos públicos para fins sociais nobres pela desconfiança em transferir à regulação os critérios de escolha dos serviços que seriam beneficiários do investimento público.

\section{Internet e Internet das Coisas (IoT)}

O ano de 2016 ficará para a história como o ano da oficialização da transição das funções da Internet Assigned Numbers Authority (IANA), controladora dos nomes de domínios da internet, para um controle multissetorial.

Em $1^{\circ}$ de outubro de 2016, o contrato de tutela da IANA pela National Telecommunications \& Information Administration (NTIA), dos Estados Unidos, expirou, abrindo caminho para que a administração multissetorial pudesse se afirmar na internet.

O modelo multissetorial de administração somente teve seus primeiros passos oficiais instaurados após o escândalo de espionagem revelado por Edward Snodew, a reação de certos países-chave ao ocorrido, a organização, pelo Brasil, do evento NetMundial, em 2014, quando, às vésperas desse evento, o Governo de Barack Obama, como o grande herói da história, declarou sua disposição oficial de abrir mão do controle da IANA. Mesmo assim, o contrato que vencia em setembro de 2015 foi renovado para atendimento de todos os critérios exigidos pelo Governo dos Estados Unidos da América, em especial, a garantia de que a administração da zona de raiz de domínios fosse multissetorial, claramente afastando-se a possibilidade de controle multilateral por parte de governos. O Brasil esteve, durante todo o processo, do lado do controle multissetorial.

Em outra frente, o governo federal brasileiro, apoiado em um convênio entre o agora Ministério da Ciência, Tecnologia, Inovações e Comunicações (MCTIC) e o Banco Nacional do Desenvolvimento (BNDES), por intermédio do Fundo de Estruturação de Projetos (FEP), contratou consultoria para realizar diagnóstico e propor políticas públicas sobre a internet das coisas, com ênfase na cooperação e articulação entre empresas, poder público e centros de pesquisa. $\mathrm{O}$ consórcio selecionado para elaboração dos estudos e propositura de políticas públicas de IoT é dirigido por uma velha conhecida do setor de 
telecomunicações, que também participou do apoio à privatização do Sistema Telebras em 1997: a consultoria internacional McKinsey, em parceria com o $\mathrm{CPqD}$ e o escritório de advocacia Pereira Neto.

Em dezembro de 2016, sob a batuta da Câmara IoT ligada à Secretaria de Política de Informática do MCTIC, em sintonia com a consultoria, lançou-se uma consulta pública no portal Participa.br para construção do Plano Nacional de IoT (internet of things ou internet das coisas) voltado a reger o setor entre os anos de 2018 e 2023, que previa treze itens estruturantes, com enfoque em temas de pesquisa e desenvolvimento, recursos humanos, investimento, suporte a aplicações e serviços, redes e transporte de dados, gateways e dispositivos, segurança e privacidade, papel do Estado e aspectos regulatórios.

Em especial, o item de demanda pública e privada tratou das chamadas verticais de aplicação de IoT, ou seja, casos de uso de IoT, e colheram contribuições para priorização de temas como saúde, agricultura, cidades inteligentes, energia, entre outros.

Quando em 2011, o então vice-presidente mundial da Microsoft esteve no Brasil à procura de políticas públicas que fornecessem um ambiente atrativo à instalação de serviços da nova economia, em especial, de data centers para a América Latina, o governo federal não tinha uma política encaminhada sobre o tema ou não quis dar a atenção a ela. A esperança é que seis anos mais tarde finalmente o Brasil possa encarar o tema com uma política abrangente e que conecte todas as nuances do ecossistema digital, que pode ser guiado pela IoT, mas que se apresenta, na verdade, como um conjunto coordenado de iniciativas para facilitação de instalação de data centers, disciplina jurídica sobre o big data, inteligência artificial, IoT, conectividade de banda larga e formação de pessoal, estes dois últimos aspectos fundamentais, que sustentam tais utilidades.

É bem verdade, entretanto, que o Brasil ocupa uma posição incômoda no tocante à IoT, assemelhando-se à Europa sem o benefício de sua indústria de ponta, que se concentra em questões de privacidade, guarda de dados e soberania das leis nacionais, bem como na preocupação com a garantia de espaço para conteúdos locais.

O movimento de consulta pública apoiado em IoT pode servir como ponto de partida para definição clara de prioridades nacionais, sejam elas commodities agrícolas e de indústria de base, infraestrutura de redes ou conteúdo digital. Como sói acontecer, o Brasil, em termos de política pública, é um país reativo, ao invés de propositivo, com intrínsecas dificuldades em se antecipar aos movimentos mundiais por seu descaso com a pesquisa e a educação. 


\section{Conjuntura e Previsões}

Em meio à maior crise econômica e política dos últimos 25 anos, em que praticamente todos os membros do alto escalão do governo haviam sido citados em delações premiadas por parte de envolvidos na Operação Lava Jato e em investigações de caixa 2 em período eleitoral, o setor de telecomunicações foi presenteado com um novo presidente e conselheiros da ANATEL, de perfil mais técnico, bem como uma reestruturação interna de superintendências que deram um novo formato mais integrado de atuação da agência em evidente maior sintonia com o Ministério supervisor.

O ano de 2017, portanto, será muito provavelmente um ano de reestruturação mais focado no funcionamento da Agência e melhor comunicação institucional, definição de grandes linhas de ação e de uma atuação de maior distanciamento dos surtos vivenciados em 2016. O real comportamento de 2017, entretanto, dependerá de como as estruturas de governo promoverão ativamente a pesquisa setorial para antecipar-se aos problemas ou permanecerão servindo como notas de rodapé de projetos de governo descontinuados e soluções momentâneas carentes de planejamento a longo prazo.

O Conselho Editorial 
